\title{
Design and Evaluation of a Scalding Animal Model by the Boiling Water Method
}

\author{
Cheng Hua ${ }^{1}$ \\ Lele Lyu' \\ Hyun Seok Ryu ${ }^{1}$ \\ So Young Park ${ }^{1}$ \\ Nam Kyu Lim² \\ Celine Abueva ${ }^{1}$ \\ Phil-Sang Chung ${ }^{1,3}$
}

${ }^{1}$ Beckman Laser Institute Korea, Dankook University, Cheonan, Korea

${ }^{2}$ Department of Plastic and Reconstructive Surgery, Dankook University Hospital, Cheonan, Korea

${ }^{3}$ Department of Otorhinolaryngology Head and Neck Surgery, Dankook University School of Medicine, Cheonan, Korea
Received March 17, 2020

Accepted April 27, 2020

\section{Correspondence}

Phil-Sang Chung

Beckman Laser Institute Korea, Dankook

University, 119 Dandae-ro, Cheonan 31116, Korea

Tel.: +82-41-550-3022

Fax: +82-41-559-7838

E-mail: pschungdadankook.ac.kr

(C) Korean Society for Laser Medicine and Surgery

(c) This is an open access article distributed under the terms of the Creative Commons Attribution NonCommercial License (http://creativecommons.org/ licenses/by-nc/4.0) which permits unrestricted noncommercial use, distribution, and reproduction in any medium, provided the original work is properly cited.

\section{Background and Objectives}

For experiments on simulated burn, the preparation of an animal model is a very important step. The purpose of the current experiment is to design a simple and controllable method for the preparation of thirddegree scald in a mouse model using the boiling water method.

\section{Materials and Methods}

A total of 18 Swiss mice were used. After the anesthetization, the mice were scalded by boiling water $\left(100^{\circ} \mathrm{C}\right)$ using a mold with a $1 \mathrm{~cm}^{2}$ circle area on the dorsum at contact times of $3 \mathrm{~s}, 5 \mathrm{~s}$, and $8 \mathrm{~s}$. After confirming that 8 seconds of scald can cause a third-degree scald, the skin samples were collected at day $2,4,6,8,10$, and 12 , and analyzed by histopathological examinations. The wound retraction index (WRI) was also measured.

\section{Results}

Third-degree scald involving full-thickness skin was observed in the 8-second scald group, while a 3-second scald caused a superficial second-degree scald and a 5-second scald caused a deep seconddegree scald. After third-degree scald, the burn wound continued to contract until day 14.

\section{Conclusion}

The scalding model of mice can be successfully established by the boiling water method. This method is easy to operate, it has a low cost, and it can control the scald depth by controlling the scald time. This is adequate to study skin thermal injury in the future. The scald model established by this method can last for 14 days.

\section{Key words}

Mouse model; Burn; Scald 


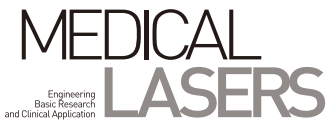

\section{INTRODUCTION}

The American Burn Association estimates that 450,000 burn patients are treated in medical institutions every year in the United States. 40000 of them need to be hospitalized, including 30000 in burn centers of specialized hospitals. 'The most common etiologies requiring burn center admission are fire/flame (43\%), followed narrowly by scalds (34\%), contact with hot objects (9\%), electricity $(4 \%)$, and chemical agents (3\%). ${ }^{2}$ Burns often cause extensive skin defects, resulting in loss of skin barrier function and inflammation. ${ }^{3-8}$ Therefore, the wound healing time caused by burns and scalds is long, the prognosis is poor and the function recovery is poor.

Generally, the burn is classified according to the depth: Superficial (first-degree) only involves skin epidermis; Superficial partial-thickness (superficial second-degree) involves superficial dermis; Deep partial-thickness (deep second-degreel involves the deeper dermis; Full-thickness (third-degree) includes the whole layer of epidermis and dermis, reaching the subcutaneous tissue, and even muscles and bones are damaged.?

Deep burns and scalds can cause scar formation, skin contracture, and serious motor dysfunction. People need to study the pathophysiological process and healing mechanism of burns and scalds to explore the healing process of burns and scalds. For burn research, in vitro models are limited in capturing various aspects of burn pathophysiology and complex clinical features of human burn. Therefore, it is necessary to establish a burn animal model to reveal the pathological mechanism after burn and test the new treatment. One of the main limitations of finding practical treatment for burn patients is the lack of an appropriate animal model that can capture all the salient features of burn wounds. However, animal models are still essential to reveal the molecular and cellular characteristics of human burn wounds. ${ }^{10}$ Qualified animal models should have the characteristics of simple operation and clear results. In the experiment of burn and scald, researchers used various animal models, including rats, mice, rabbits, pigs, etc. ${ }^{10-12}$ Mice are one of the most commonly used animal models to study burn and wound healing. As a research model, due to the feasibility of a variety of mouse specific reagents and transgenic mice, this animal provides great convenience for researchers to study the signal pathway involved in the healing process. ${ }^{10}$ In addition, the incidence rate of diseases in mice in the study group was very low due to the significant reduction in healing time ${ }^{13}$ and superior in the immune system. ${ }^{14}$ In this study, we used boiling water method to make third- degree burn animal models in mice. It has the advantages of simple operation, strong reproducibility, uniform depth and scope of injury. With this method, it is easy to obtain a large number of models with the same conditions, so as to improve the comparability and repeatability of the experimental results and make the results more accurate.

\section{MATERIALS AND METHODS}

\section{Experimental animals}

This research protocol was approved by the Dankook University Medical School Research Institutional Animal Care and Use Committee. Eighteen healthy male swiss mice aged 8 weeks were provided by ORIENTBIO Company (Seongnam, Korea) and reared under clean conditions for one week. The preoperative mice weighed 35-36 grams. The experiment was divided into two steps. Step 1 is to clarify the relationship between scald time and scald depth. ${ }^{12}$ mice were randomly assigned to three equal groups according to scalding time: (1) scalding time 3s; (2) scalding time 5s; (3) scalding time 8s. Step 2 is to observe the healing process of the third-degree scalded mice. After confirming that 8 s scald can cause third degree scald, 12 mice were given 8 s scald and randomly divided into 6 groups. On day 2, 4, 6, 8, 10 and 12, two mice were randomly selected for tissue sampling each day.

\section{Experimental materials}

Narcotics is a combination of tiletamine-zolazepamxylazine (Zoletil $^{\mathrm{TM}} 50$, Virbac, TX, USA; Rompun ${ }^{\circledR}$, Bayer, Leverkusen, Germany), self-made scald mold $115 \mathrm{ml}$ plastic centrifugal tube was used to cut off the tip to form a circular defect with a diameter of $1.13 \mathrm{~cm}$ and an area of about $1 \mathrm{~cm}^{2}$ l, alcohol lamp, flask, flask holder, $10 \mathrm{ml}$ pipette, electric pipetting Electric pusher, stopwatch, hair removal paste, lighter, electric warm pad, etc.

\section{Scalding method}

Mice were anesthetized and shaved clean prior to treatment. To make the scald, distilled water was poured into the flask and heated using an alcohol lamp. The temperature of boiling water is determined to be $100^{\circ} \mathrm{C}$. One person presses the scald mold on the back of the mouse, avoid using too light force to make water flow out or using too heavy force to damage the mouse skin. Another person uses a pipette to suction $10 \mathrm{ml}$ of boiling water, quickly inject it into the mold, 3 seconds, 5 seconds or 8 seconds later, pour out the boiling water, and spray cold water for cooling (Fig. 1). After scalding, the mice were placed on an electric warm pad to prevent hypothermia 
and shock. After recovery, the mice were returned in their respective cages and fed normally.

\section{Observation of scald wound contraction}

Scald area were photographed at 4, 6, 8, 10, 12 and 14 days to observe wound contraction. Lesions were photographed with a digital camera at a standard distance
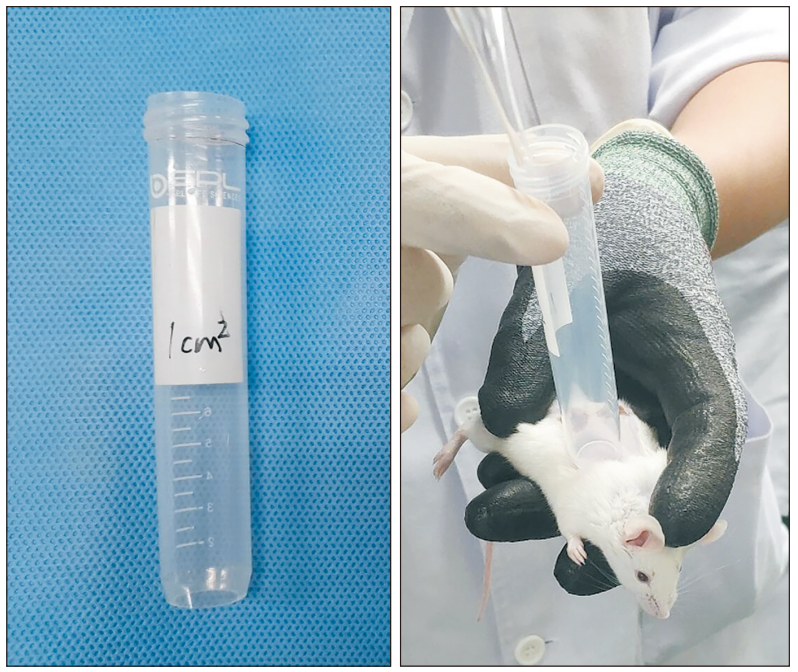

Fig. 1. Methodology of burn wound creation. Use a $15 \mathrm{ml}$ centrifugal tube with the tip removed to make a scald mold. Add $10 \mathrm{ml}$ boiling water into the tube when scalding. The opening area of centrifugal pipe is $1 \mathrm{~cm}^{2}$. of $15 \mathrm{~cm}$. Adobe Photoshop CC (Adobe Systems, Mountain View, CA, USA) was used to measure the size of the wound (Unit: pixel area). The region of interest (ROI) was carefully selected using an elliptical marquee tool drawn around the wound area. WRI was determined from the selected ROI and calculated by the following equation: WRI $(\%)=$ (initial area - area on the day of euthanasia) $\div$ initial area $\times 100 .^{15}$ The water intake of mice was observed and the weight of mice was measured by electronic scale.

\section{Histological examination of skin}

On the 4th, 6th, 8th, 10th, 12th day after scald, the scald wounds were cut off after anesthesia. After flattening and fixing, the wounds were immersed in $10 \%$ formalin solution. Paraffin sections were prepared by conventional method, and the thickness of the sections was $7 \mu \mathrm{m}$. After hematoxylin-eosin (H\&E) staining, Olympus microscope (DP74; Olympus, Tokyo, Japan) was used to observe and photograph.

\section{RESULTS}

After scalding mice with boiling water, there were regular circle scald wounds on the back of experimental mice without blisters and exudation. The mice were observed to be in poor mental and dietary condition.

A

Normal skin tissue

Skin tissue after 3s scald

Skin tissue after 5 s scald

Skin tissue after 8 s scald
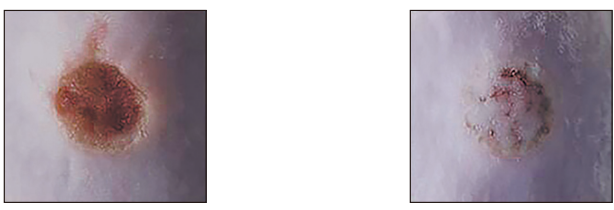

B

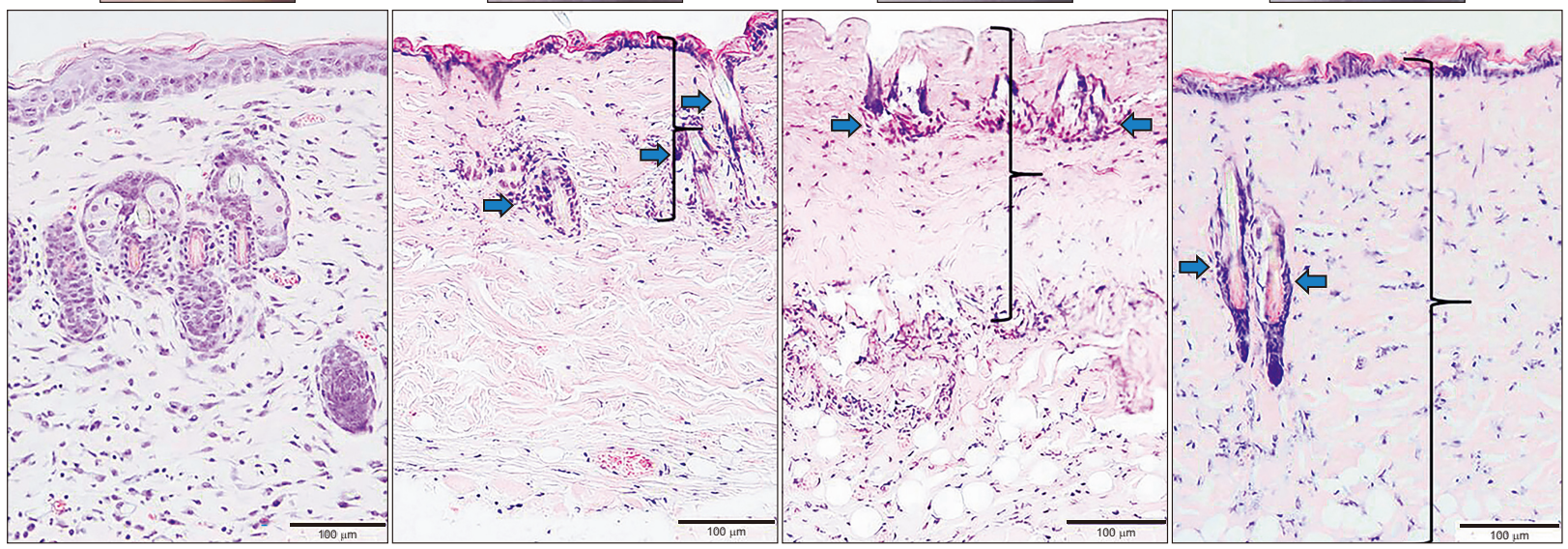

Fig. 2. The condition of the wound 48 hours after scalding (A) and their corresponding histological sections (B). Sections were stained with hematoxylin \& eosin (H\&E). Scale bar: $100 \mu \mathrm{m}$. Black lines indicate collagen coagulation depth, while the arrows show the follicles and glands that were damaged during the scald. 


\section{Determine the depth of scald}

In order to find out the relationship between the time and the depth of scald, we made 3 seconds, 5 seconds and 8 seconds scald wounds respectively, and made histological examination after scald (Fig. 2).

Forty-eight hours after scald, tissue in the scald area was necrosed as observed in (Fig. 2), and blood crust have not formed yet, there were obvious regular round scald wounds on the back of experimental mice, without blisters and exudation (Fig. 2A). The epithelial tissue structure is incomplete and the epithelial cells are atrophic and necrotic. Meanwhile, the structures of skin appendages and glands was atrophic. Hair follicles in the dermis were destroyed. The morphology of dermis was abnormal, indicating necrosis. Scald leads to the degeneration of collagen in the dermis and changes the cord like collagen fiber into hyaline necrosis tissue. There was no neovascularization in dermis. After 3 seconds of scalding, the wound depth reaches to the superficial dermis, which can be determined as superficial second-degree scald. After 5 seconds of scalding, the depth of the wound reaches deep dermis, which can be determined as deep second-degree scald. After 8 seconds of scalding, the depth includes the whole skin layer and reaches the subcutaneous fat layer, which can be determined as third-degree scald (Fig. 2B). ${ }^{9}$ Since the experiment usually requires a long healing time to determine the effect of treatment, we choose the third- degree burn as the main study object. The mice were in poor mental state and poor diet.

\section{Changes of scalded wounds}

Fig. 3 shows the changes of wounds in mice after scalding. On day 4, blood crust appeared on the wound surface and the wound partly contracted.

From day 4 to day 6 , the wound contracted most in this period $(p<0.005)$. On day 8 , the crust on the surface of the wound was partly raised and some epithelium could be seen under the crust. On day $14,82.3 \%$ of the wounds were healed.

\section{Histological changes of scalded wounds}

In normal skin tissue (Fig. 4A), the epidermis and dermis are intact. Collagen fibers in dermis were distributed regularly and the hair follicles and skin organs are plump. There are normal vessels in the dermis.

On day 2 after scald (Fig. 4B), the necrosis of tissue in the burn area was formed, and no blood crust was found. Epithelial tissue structure is incomplete and epithelial cells atrophy and necrosis. The collagen cells in the dermis lost normal fibrous structure and exhibits hyaloid or caseous necrosis. Skin appendages and lands are atrophic in morphology and abnormal in structure. Hair follicles were destroyed. Compared with normal skin (279.7 \pm 33.9), the number of nucleated cells in dermis decreased

\section{A}
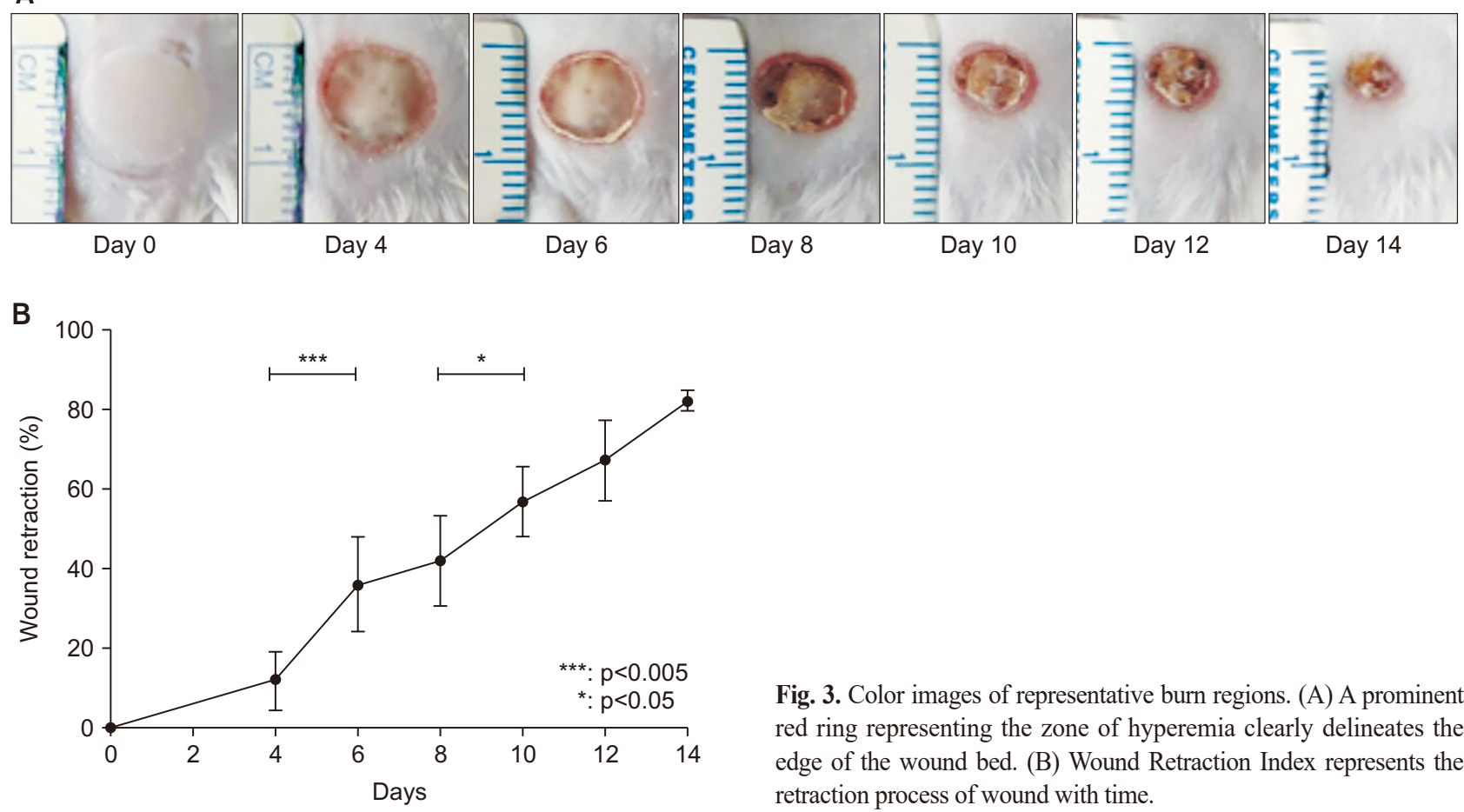

Fig. 3. Color images of representative burn regions. (A) A prominent red ring representing the zone of hyperemia clearly delineates the edge of the wound bed. (B) Wound Retraction Index represents the retraction process of wound with time. 

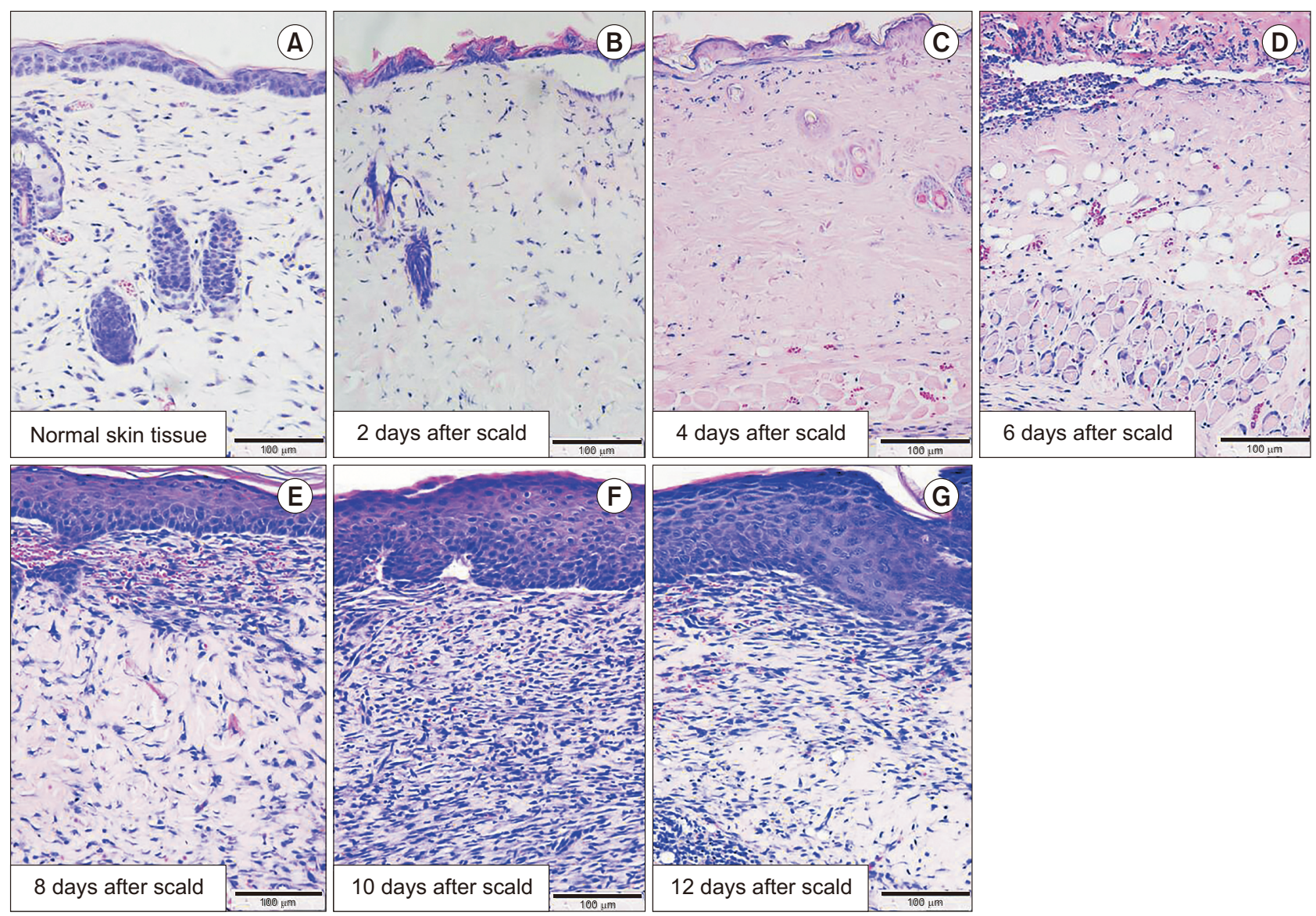

Fig. 4. Histological evaluation of wounds in different periods. Scale bar: $100 \mu \mathrm{m}$. (A) Normal skin tissue. (B) One day 2, The epidermis is atrophic and the structure of epidermis cell is abnormal. The collagen cells in the dermis showed hyaline or caseous degeneration. (C) On day 4, collagen is still necrotic and the number of nucleated cells in the dermis is decreased. (D) On day 6, blood crust formed, inflammatory cells and necrotic cells were found at the junction of the crust and dermis. There was angiogenesis formed in the dermis. (E) On day 8, epithelial cells were formed and the new epithelial layer was thicker than normal skin. The morphology of collagen fibers in dermis began to recover. (F) On day 10, epithelial layer was thicker. Inflammatory cells filled the dermis. $(\mathrm{G})$ On day 12, the morphology of collagen in dermis was improved and the number of inflammatory cells in dermis was decreased.

significantly (164.5 $\pm 14.8, p<0.005)$, and the morphology was abnormal, suggesting necrosis. There was no neovascularization in dermis. The scald depth includes the whole skin layer, reaching the subcutaneous fat layer, which can be determined as the third-degree scald.

On day 4 after scald (Fig. 4C), there was still necrosis in the epidermis and dermis. The epidermis was filled with collagen fibers without epithelial tissue formation. The dermis is filled with a large number of collagen fibers arranged in parallel, and exhibits hyaloid or caseous necrosis. Skin appendages were disappeared with no angiogenesis. Compared with day 2 (164.5 \pm 14.8 ), the number of nucleated cells in dermis was further reduced $(63.5 \pm$ $12.2, p<0.005)$, and there was no infiltration of inflammatory cells.

On day 6 after scald (Fig. 4D), blood crust formation was observed in the scalded part, but no epidermal formation was observed. A large number of inflammatory cells and necrotic cells were found at the junction of the crust and dermis. At this time, no skin appendages and glands were found in the dermis, but there was angiogenesis formed.

On day 8 after scald (Fig. 4E), there were new epidermal cells covering the surface of dermis, and the new epithelial layer was thicker $(63.84 \pm 13.45 \mu \mathrm{m})$ than normal skin $(31.21 \pm 11.3 \mu \mathrm{m}, p<0.005)$ and mainly composed of acanthocytes. Inflammatory cell infiltration was observed at the junction of epidermis and dermis. The morphology of collagen fibers in dermis began to recover, accompanied by the formation of neonatal cells with regular morphology.

On day 10 after scald (Fig. 4F), epithelial layer was thicker $(127.96 \pm 20.63 \mu \mathrm{m})$ than that on day $8(63.84 \pm 13.45 \mu \mathrm{m}$, 


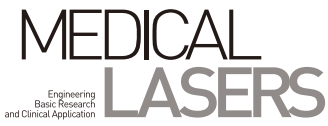

$p<0.005$ ). The increase of epidermis thickness mainly depends on the thickening of basal layer. Inflammatory cells filled the dermis. Collagen fibers were arranged in parallel.

On day 12 after scald (Fig. 4G), the morphology of collagen in dermis was improved and the number of inflammatory cells in dermis was decreased. The morphology of dermis was not different from that at day 10 .

\section{DISCUSSION}

Burn and scald is a serious and complex injury. Despite the limitations of using animal models to simulate human burn and scald, rodents have been accepted as good model carriers to simulate burn and scald. ${ }^{16}$ Because of low cost, low incidence rate of disease ${ }^{13,14}$ and the existence of multiple transgenic mice, mouse model is very convenient as animal model, and has advantages in the research of burn as well. ${ }^{10}$

Techniques that have been used to generate burn surfaces in experimental animal models include direct contact with a heated metal, ${ }^{11,17,18}$ burning fuel, ${ }^{19}$ electricity, ${ }^{20}$ and heated water. ${ }^{11,21,22}$ The method of heating metal blocks can effectively control scald area and scald time, but the back surface of mice is non-planar. Different pressure in different areas may affect the depth of scald. In addition, the temperature of the metal block by heating is not easy to control, and the heat dissipation is faster, which may cause larger errors in the experiment. The drawback of this method is the lack of a homogenous uniform burn depth. The method of heating phosphate powder is direct burn, which can simulate the burn process in life. However, high concentration of phosphorus itself has a certain toxicity, which will cause organ damage in the whole body after absorption, ${ }^{23}$ and white phosphorus burning point is low and flammable, storage risk is large. Electrical burns usually require higher animals, such as monkeys, to achieve damage similar to that of humans. ${ }^{20}$ Among the above models, the boiling water model has been widely used, which is considered as the standard of burn animal model by some experts. Burns caused by hot liquids are the most common cause of burns in children and the elderly. ${ }^{10}$ Moreover, scalding is the easiest mechanism of provoking an experimental dermal burn. The possibility of varying water temperature, time of exposure and the burned area makes this method ideal for reproducing almost every kind of thermal aggression. ${ }^{11}$ The method of whole-body scald of mouse has a large wound, which is only suitable for simulating large area scald process. In this experiment, we designed a standardized method, using self-made mold and boiling water to create $1 \mathrm{~cm}^{2}$ scald wounds, and obtained thirddegree scald wounds with uniform scald area and depth. The experimental model is easy to operate and low cost. It has the characteristics of constant scald time, constant scald pressure and constant scald area. As a result, it can ensure that every scald wound has the same pathological characteristics and does not cause excessive damage to animals. This is the key factor in making animal models.

In our study, we used the method of boiling water ${ }^{24}$ scalding for 3 seconds, 5 seconds, 8 seconds, and the obtained wound was proved to be superficial seconddegree, deep second-degree, and third-degree scald by histological analysis. In the actual experiment, the desired depth of scald can be obtained by adjusting the scald time according to the need of the experiment. In our experiments, we found that the process of collagen changes and wound recovery was similar to that of human, but the time of inflammation was different. Inflammatory exudation did not occur in the burned area of mice until day 4 , whereas inflammatory exudation occurred immediately after human skin burns. The reasons for this difference are not clear, and need to be further studied and solved.

\section{ACKNOWLDEGEMENTS}

We thank Beckman Laser Institute Korea, Dankook University, for providing necessary financial assistance and the experimental equipment and animals. We also thank Prof. Abueva for useful comments and language editing which have greatly improved the manuscript.

\section{CONFLICT OF INTEREST}

The authors have no conflict of interest to disclose.

\section{REFERENCES}

1. Toussaint J, Singer AJ. The evaluation and management of thermal injuries: 2014 update. Clin Exp Emerg Med 2014;1:818.

2. Bessey PQ, Phillips BD, Lentz CW, Edelman LS, Faraklas I, Finocchiaro MA, et al. Synopsis of the 2013 annual report of the national burn repository. J Burn Care Res 2014;35 Suppl 2:S218-34

3. Lee SJ, Suh JH, Kang JM, Kim YK, Chung WS, Kim BJ, et al. Treatment of burn scars with the pinhole 4.0 method using a 10,600-nm carbon dioxide laser. Med Lasers 2015;4:70-3.

4. Lee HJ, Kim YK. Burn wound successfully treated with 830$\mathrm{nm}$ light emitting diode phototherapy combined with epidermal 
growth factor solution. Med Lasers 2019;8:94-6.

5. Lee WS, Park ES, Kang SG, Tak MS, Kim CH. Successful treatment of recalcitrant remaining postoperative wounds by dualfrequency ultrasound. Med Lasers 2018;7:74-8.

6. Choi YS, Khan G, Nam SM, Park ES. Successful treatment of post-traumatic elbow scar contracture using combined approach of surgical release \& early fractional laser resurfacing. Med Lasers 2018;7:32-7.

7. Rhee YH, Cho KJ, Ahn JC, Chung PS. Effect of photobiomodulation on wound healing of the corneal epithelium through RhoGTPase. Med Lasers 2017;6:67-76.

8. Hong SW, Park ES. Granuloma formation, a rare complication after PDO threads lifting, and adjuvant treatment using dualfrequency ultrasound (LDM ${ }^{\circledR}$-MED). Med Lasers 2019;8:35-8.

9. Warby R, Maani CV. StatPearls- burns classification [Internet]. Treasure Island (FL): StatPearls Publishing; c2019. [cited 2020 Mar 1]. Available from: http://www.ncbi.nlm.nih.gov/books/ NBK539773/.

10. Abdullahi A, Amini-Nik S, Jeschke MG. Animal models in burn research. Cell Mol Life Sci 2014;71:3241-55.

11. Dahiya P. Burns as a model of SIRS. Front Biosci (Landmark Ed) 2009;14:4962-7.

12. Sullivan TP, Eaglstein WH, Davis SC, Mertz P. The pig as a model for human wound healing. Wound Repair Regen 2001;9:66-76.

13. Wong WW, Sorkin M, Glotzbach JP, Longaker MT, Gurtner GC. Surgical approaches to create murine models of human wound healing. J Biomed Biotechnol 2011;2011:969618.

14. Mestas J, Hughes CC. Of mice and not men: differences between mouse and human immunology. J Immunol 2004; 172:2731-8.

15. de Alencar Fernandes Neto J, Nonaka CFW, de Vasconcelos Catão MHC. Effect of blue LED on the healing process of thirddegree skin burns: clinical and histological evaluation. Lasers
Med Sci 2019:34:721-8.

16. Erdle BJ, Brouxhon S, Kaplan M, Vanbuskirk J, Pentland AP. Effects of continuous-wave (670-nm) red light on wound healing. Dermatol Surg 2008;34:320-5.

17. Singer AJ, Taira BR, Lin F, Lim T, Anderson R, McClain SA, et al. Curcumin reduces injury progression in a rat comb burn model. J Burn Care Res 2011;32:135-42.

18. Campelo AP, Campelo MW, Britto GA, Ayala AP, Guimarães $\mathrm{SB}$, Vasconcelos PR. An optimized animal model for partial and total skin thickness burns studies. Acta Cir Bras 2011;26 Suppl 1:38-42.

19. Higashimori H, Whetzel TP, Mahmood T, Carlsen RC. Peripheral axon caliber and conduction velocity are decreased after burn injury in mice. Muscle Nerve 2005;31:610-20.

20. Zelt RG, Daniel RK, Ballard PA, Brissette Y, Heroux P. Highvoltage electrical injury: chronic wound evolution. Plast Reconstr Surg 1988:82:1027-41.

21. Walker HL, Mason AD Jr. A standard animal burn. J Trauma 1968;8:1049-51.

22. Dinar S, Sen C, Unal C, Agir H, Iscen D. A new material for the standard burn model: Allevyn adhesive. Plast Reconstr Surg 2006;117:717-8.

23. Barqouni L, Abu Shaaban N, Elessi K. Interventions for treating phosphorus burns. Cochrane Database Syst Rev 2014;(6):CD008805.

24. Lee JA, Jeong HJ, Park HJ, Jeon S, Hong SU. Acupuncture accelerates wound healing in burn-injured mice. Burns 2011;37:117-25.

How to cite this article: Hua C, Lyu L, Ryu HS, Park SY, Lim NK, Abueva C, Chung PS. Design and evaluation of a scalding animal model by the boiling water method. Med Lasers 2020;9:51-57. https://doi.org/10.25289/ML.2020.9.1.51 